\title{
ADDENDUM: DERIVATIVES OF INFINITE ORDER
}

\author{
R. P. BOAS, JR., AND K. CHANDRASEKHARAN
}

We gave an incomplete proof ${ }^{1}$ that, if $f(x)$ belongs to a quasianalytic class $C\left\{M_{n}\right\}$ in $a<x<b$ and if $f^{(n)}\left(x_{0}\right) \rightarrow L$ for one $x_{0}$ in $(a, b)$, then $f(x)$ is analytic in $(a, b)$ (and consequently $f^{(n)}(x) \rightarrow L e^{x-x_{0}}$ in $a<x<b)$; the proof was completed by S. Mandelbrojt. ${ }^{2}$ We now wish to point out that in fact T. Bang ${ }^{3}$ had already shown that if $f(x)$ belongs to a quasi-analytic class on $a<x<b$ and $g(x)$ is analytic, then $f^{(n)}\left(x_{0}\right)=g^{(n)}\left(x_{0}\right)$ for all $n$ and $a<x_{0}<b$ implies $f(x) \equiv g(x)$, which is precisely the result which we needed for our proof.

Bang has also pointed out to us that a function constructed in his thesis ${ }^{4}$ answers a question raised by us. ${ }^{5}$ We asked whether it is possible to have $\lim _{n \rightarrow \infty} f^{(n)}(x) / \lambda_{n}=g(x), a \leqq x \leqq b$, with lim inf $\left|\lambda_{n-1} / \lambda_{n}\right|$ $=0$, and $g(x) \neq 0$ in $a<x<b$. Bang constructed a function $f(x)$ analytic except for $x=0$, with $f^{(n)}(0)$ tending to $\infty$ arbitrarily rapidly; if we take $\lambda_{n}=\left|f^{(n)}(0)\right|$, we have $g(x)=0$ for $x \neq 0, g(0)=1$.

BROWN UNIVERSITY AND

INSTITUTE For Advanced StUdy

Received by the editors June 25,1950 .

${ }_{1}^{1}$ Derivatives of infinite order, Bull. Amer. Math. Soc. vol. 54 (1948) pp. 523-526.

2 R. P. Boas and K. Chandrasekharan, Correction: Derivatives of infinite order, Bull. Amer. Math. Soc. vol. 54 (1948) p. 1191.

${ }^{3}$ T. Bang, Om quasi-analytiske Funktioner, Copenhagen thesis, 1946, p. 84.

4 Bang, loc. cit.

${ }^{5}$ Boas and Chandrasekharan, op. cit., p. 525. 